\title{
Aristóteles introducido por Juan Gerson: La teoría de la conquista de Vasco de Quiroga (1470?-1565)
}

Aristotle introduced by Jean Gerson: The Theory of the Conquest of Vasco de Quiroga (1470?-1565)

Christian SchäFer

Universität Bamberg, Alemania christian.schaefer@uni-bamberg.de

DOI: https://doi.org/10.15366/bp2021.26.002 Bajo Palabra. II Época. No26. Pgs: 39-58 
Recibido: 30-08-2020

Aceptado: 20-09-2020

\section{Resumen}

En su Información en Derecho, Vasco de Quiroga (1470?-1565) discute la teoría de la guerra justa de su tiempo, proponiendo una perspectiva muy suigeneris del problema. Desestima e incluso ataca las doctrinas tradicionales justificatorias de la Conquista, que procuraron legitimarla por la idolatría, la agresión contra los españoles, o las infracciones contra la ley natural por parte de los indígenas. Por su lado, Quiroga elabora una teoría que, basada en la filosofía política de Aristóteles, permite la conquista del Nuevo Mundo arguyendo que no existía autoridad política legítima en la América precolombina. En este artículo, intentaré dilucidar esta interpretación quiroguiana de Aristóteles y la aplicación de esta interpretación al caso de la Nueva España.

Palabras clave: Vasco de Quiroga, Conquista, guerra justa, Aristóteles, Juan Gerson, utopia, filosofia politica.

\section{Abstract}

In his Información en Derecho, Vasco de Quiroga (1470?-1565) discusses the just war theory of his times, proposing an own take on the subject. He dismisses, and occasionally attacks traditional attempts to justify the Spanish Conquista, which argued that the conquest was justifiable, because the American natives were idolaters, aggressors against the Spaniards, or infringers of Natural Law. Yet, he puts forward a theory which, based on Aristotle's political thought, allows for a conquest of the New World alleging that there was no legitimate political authority whatsoever in pre-Columbian America. In this paper, I try to get to grips with Quiroga's interpretation of Aristotle and his application of this interpretation to the peoples of New Spain.

Keywords: Vasco de Quiroga, Conquest, just war theory, Aristotle, Jean Gerson, utopia, political philosophy. 
La Información en Derecho de Vasco de Quiroga [en adelante, 'IeD'] fue escrita, enviada y dirigida a un alto funcionario del Consejo de Indias en 1535. Es un documento de carácter muy heterogéneo, pues combina la dilucidación jurídica, la discusión filosófico-teológica, el informe político y la explicación etnológica. Pero el objetivo principal del escrito es la discusión y crítica de la legitimidad de lo que la Segunda Provisión de la Corona espańola había decretado sobre el tratamiento de los indígenas de la Nueva España revocando las instrucciones de una provisión anterior, la primera, a este respecto. La Segunda Provisión permitía esclavizar e, incluso, marcar a fuego a los indígenas bajo determinadas circunstancias (medidas estas que justamente había prohibido la anterior). ${ }^{1}$ Una de estas circunstancias justificatorias era que se les hubiera capturado en el curso de una guerra justa, la cual queda definida en la mencionada provisión como un enfrentamiento armado provocado por los indígenas en caso de rebelión, de intrusión violenta, de resistencia a la predicación cristiana, de robo de la propiedad de los españoles o de obstrucción a la libre circulación. En lo siguiente, discutiré la teoría de la guerra justa en la crítica que Quiroga hace a la provisión y la enlazaré con la teoría de la Conquista que propone Quiroga basándose en la filosofía política de Aristóteles.

\section{La legitimación de la esclavitud indígena en la Segunda Provisión}

En Su CRÍtica a los Razonamientos y los parámetros que establece la Segunda Provisión para legitimar la esclavitud de los sometidos en guerra justa, Quiroga es contundente. Mantiene taxativamente que no se puede hacer una guerra justa a los naturales sirviéndose de los motivos que estipula la provisión: "las condiciones y limitaciones con que se justifica son imposibles, que no se pueden efectuar ni aplicar al hecho" (IeD, 93). Consecuentemente, sería un despropósito aplicar este concepto de guerra justa para legitimar la esclavitud de los capturados en ella:

\footnotetext{
${ }^{1}$ Sobre las provisiones, su historia y su contenido cf. Martín Hernández, F., Vasco de Quiroga, Salamanca: Publicaciones UPS 1993, pp. 154-155.
} 
Porque en cuanto a los esclavos de guerra, no se hallará, en hecho de verdad, para que se pueda justificar la guerra contra estos naturales, como la provisión lo requiere, que ellos nos infesten, molesten ni impidan paso, ni recobranza de cosa nuestra, ni se rebelen, ni resistan la predicación evangélica (IeD, 92).

Quiroga hace una distinción muy importante que se encuentra asimismo en muchos tratadistas espańoles de la época. Si bien es cierto que, por un lado, niega todo derecho a hacer esclavos en el caso concreto de aquellas guerras de conquista frente a los indios, no por ello niega que pueda haber, en general, una tal guerra justa en contra de indígenas y con el objetivo de conquistarlos, ni niega al mismo tiempo el derecho, basado en la tradición aristotélica, a hacer esclavos a los ya vencidos en una guerra semejante. Lo que rechaza es que la conquista, tal como se había llevado a cabo previamente y como después, en su época, continuaría desarrollándose, fuera de hecho una guerra justa. Ya veremos más adelante cómo se explica esta opinión que, a primera vista, puede resultar un tanto paradójica. Por lo pronto, baste seguir las indicaciones que Quiroga mismo da al hablar sobre la resistencia de los indígenas a la labor misionera de los españoles como supuesta causa legítima de una guerra justa, tal y como la define la provisión. A Quiroga le consta que esta causa sería legítima sólo si se cumpliera

con los requisitos necesarios y como tengo dicho: yendo a ellos como vino Cristo a nosotros, haciéndoles bienes y no males, piedades y no crueldades, predicándoles, sanándoles y curando los enfermos, y, en fin, las otras obras de misericordia y de la bondad y piedad cristiana (IeD, 92).

En caso contrario, no existe ninguna legitimación posible de la guerra. Pues bien, la realidad histórica habría representado una situación bien distinta de la que aquí se especifica, como Quiroga no se cansa de repetir en el trascurso de su Información. ${ }^{2}$

\section{La teoría de la guerra justa en Cayetano}

QUiRoga ACLARA QUE SU IDEAL DE UNA CONQUISTA PACÍFICA Y ESPIRITUAL deriva del célebre Comentario a la Summa Theologiae de Cayetano: uno de los textos más

\footnotetext{
${ }^{2}$ Quiroga en numerosas ocasiones insiste, por el contrario, en que los motivos de la Conquista en realidad han sido la codicia, la soberbia, las ambiciones personales, etc. Cf. Serrano Gassent, P., Vasco de Quiroga: La Utopía en América. Madrid: Dastin, 2002, pp. 74; 79-80; 86; 92; 101; 121; 126; etc.
} 
citados y recurrentes en la querella de la Conquista durante el siglo XVI. Quiroga se apoya en el siguiente pasaje del Comentario:

Deberían ser enviados (como dice por otro tanto como esto el Cayetano, 2a 2ae q. 66 artículo octavo) a los tales [indígenas] predicadores que, siendo santos varones, los conviertan a Dios con la palabra y el ejemplo; y no que los opriman, despojen, escandalicen, sometan y a la manera de los fariseos los hagan doblemente hijos del infierno ${ }^{3}$ (IeD, 93).

En esto, según aclara Quiroga reiteradamente, Cayetano tiene toda la razón y hay que seguirle en su planteamiento. Sin embargo, Cayetano prosigue con un argumento en contra de toda posibilidad de hacerles guerra legítima a los infieles del Nuevo Mundo, y en esto empezamos a ver discrepancias respecto a lo que mantiene Quiroga. Cayetano señala que hay tres clases de infieles:

(1) los que habitan en territorio de cristianos y son súbditos de los cristianos tanto de iure como de facto, como es el caso de los judíos y los herejes (que, sin embargo, no son infieles en el sentido pleno de la palabra), y como es el caso también de los musulmanes, en la medida en la que todos ellos habitan en territorios de príncipes cristianos. A éstos, no está permitido hacerles la guerra, pero se los puede justamente llegar a despojar de sus bienes materiales (como a través de ciertos impuestos especiales o de las expropiaciones);

(2) los infieles que ocupan territorios antiguamente controlados por cristianos, como en la práctica es el caso de todos los infieles que viven en el territorio de la antigua ecúmene, esto es, del antiguo Imperio Romano cristianizado. Tal es el caso de muchos musulmanes que por esta razón se han de considerar súbditos de los cristianos de iure, aunque no lo sean de facto. El corolario es que estos musulmanes son infieles que se encuentran, esta vez tanto de iure como de facto, en un estado de rebelión contra los cristianos, cuyos territorios ocupan:

en cuanto a hacer la guerra a tales infieles, cualquier gobernante cristiano que tenga autoridad de declarar la guerra por la propia república puede hacerla a dichos infieles contando con el voto común del pueblo cristiano, aunque sea tácito, y puede poseer lícitamente lo que llegue a obtener, siempre que no sobreviva algún heredero cristiano; pues, si sobrevive, ha de restituírsele lo suyo (IeD, 94).

\footnotetext{
${ }^{3}$ Reproducimos aquí (así como en las citas siguientes) la traducción de Serrano Gassent del pasaje correspondiente de Cayetano en latín.
} 
Con esto, en la taxonomía de los infieles de Cayetano, figuran hasta ahora: los no cristianos, que sin embargo no son infieles propiamente dichos (p.ej. los judíos), y los infieles, que, sin embargo, no son paganos propiamente dichos (p.ej. los musulmanes);

(3) En cuanto al tercer caso de los paganos propiamente dichos, la opinión de Cayetano se resume en los siguientes términos:

ni de derecho ni de hecho están sujetos a los príncipes cristianos conforme a la jurisdicción civil. Tal es el caso de aquellos paganos que nunca fueron súbditos del Imperio Romano y que habitan tierras jamás nombradas como de cristianos. Las autoridades de esos lugares, aunque infieles, son legítimas autoridades, sea que se gobiernen de acuerdo al sistema regio, sea que se ajusten al régimen de participación ciudadana. [...] Contra estos últimos infieles, ningún rey, ningún emperador, ni la Iglesia romana, puede mover guerra para ocupar sus tierras o para sujetarlos políticamente, puesto que no hay ninguna causa de guerra justa. Jesucristo, rey de reyes, a quien ha sido dada toda potestad en el cielo y en la tierra, envió para la conquista del mundo no soldados con armamento, sino predicadores santos, como ovejas entre lobos. [...] En consecuencia, nosotros pecaríamos gravísimamente, si pretendiésemos dilatar la fe de Cristo Jesús por este camino. No llegaríamos a ser sus legítimos señores, sino cometeríamos grandes latrocinios y quedaríamos obligados a la restitución, como responsables de una guerra injusta (IeD, 94-95).

Quiroga está de acuerdo con la teoría taxonómica de Cayetano, pero advierte que, en el tercero (y último) de los casos mencionados, Cayetano se refiere a infieles de un nivel cultural mínimo. En contraste con ello, según Quiroga, los bárbaros del Nuevo Mundo son más 'salvajes' ${ }^{4}$ que 'bárbaros'. A diferencia de los infieles de los que habla Cayetano, que tienen legítimas autoridades y "se gobiernan de acuerdo al sistema regio" o "se ajustan al régimen de participación ciudadana" y que tienen "ordenanzas buenas por donde se rigen y gobiernan" ( $\mathrm{IeD}, 96)$, los infieles del Nuevo Mundo eran tan bárbaros que les faltaría toda base imprescindible para el autogobierno. Según esto, habrían vivido y, en algunos casos, seguían viviendo en un orden social privado de toda civilización que desconocía autoridades legítimas y que, por ello, más debía en rigor llamarse desorden u orden social deficiente. Este desorden, según el análisis de Quiroga, se genera justamente por la falta de una buena policía.

\footnotetext{
${ }^{4}$ El sentido de 'salvaje' en cuanto falto de toda organización y afiliación política se hará patente en lo que sigue. El término 'salvaje' deliberadamente denigrante como se utiliza desde el s. XVII en adelante, no tiene correspondencia en Quiroga, a no ser que la palabra 'silvestre', que Quiroga (como otros autores de la época) reserva para ciertas formas de vida 'salvajes', concuerde con ciertos aspectos del 'salvaje' de la acepción moderna.
} 


\section{El concepto de "buena policía" en Quiroga}

"Buena policía" es un término Clave en la obra de Quiroga. No en vano se ha discutido mil veces qué es lo que exactamente se ha de entender por semejante "buena policía". El Diccionario de la Real Academia Española define policía como "[b]uen orden que se observa y guarda en las ciudades y repúblicas, cumpliéndose las leyes u ordenanzas establecidas para su mejor gobierno", a lo que añade, como significado caído en desuso: "Cortesía, buena crianza y urbanidad en el trato y costumbres". Empecemos, entonces, por señalar que ambos significados efectivamente convergen en el concepto de buena policía que utiliza Quiroga. A partir de estas aclaraciones y apoyándonos, además, en lo visto hasta ahora en la progresión de la argumentación quiroguiana que encontramos en la Información en Derecho y, finalmente, en vista de cómo Quiroga emplea el término en sus Reglas y Ordenanzas para los Pueblos-Hospitales [RyO], ${ }^{5}$ vamos a entender en adelante por "buena policía":

(1) un régimen social (en el doble sentido que tiene la palabra "régimen", a saber, como forma de gobierno' y como 'modo de vida') que

(2) posibilita y, en última instancia, efectivamente da como resultado una convivencia provechosa de todos los miembros del grupo ordenado socialmente por dicho régimen,

(3) tanto del conjunto, como, en la medida de lo posible, de cada uno de sus integrantes.

De esta definición trigradual se desprende, entonces, que el elemento definitorio "bueno" en "buena policía" se refiere a la capacidad de cumplir con la eficacia implicada en el término "provechosa" en relación con el orden social así establecido. Hay que advertir, que los términos "provechoso" y "eficacia", que en su uso contemporáneo conllevan un predominante aspecto utilitarista, en Quiroga se extienden "[a]l trato y costumbres", tal como lo indica con razón el diccionario de la Real Academia; y, en especial, a consideraciones morales y religiosas (por lo que, en este sentido, podríamos decir, que quedan referidos a un eudemonismo social). Esto es precisamente lo que se deduce del empleo que, dentro de la expresión "buena policía", se hace de la palabra "buena" en las Reglas y Ordenanzas. ${ }^{6}$

\footnotetext{
${ }^{5}$ Cf., por ejemplo, Serrano Gassent, P., (RyO), Vasco de Quiroga: La Utopía en América, op. cit, p. 256: "sin cuidado de sus prójimos, como es cosa verosímil que sería, y se suele hacer por nuestros pecados, y por falta de semejante policía, y concierto de República, que es procurar lo propio, y menospreciar lo común”; RyO, 257: "quitándoos lo malo, y dejándoos lo bueno de vuestras costumbres, manera, y condición, como en toda buena policía”; etc.

${ }^{6}$ Ibid., p. 254: "para vuestra utilidad, y provecho in utroque homine que es así para el ánima como para el cuerpo, y para vuestra buena policía, y prudencia, que tengáis en las cosas de que en la verdad mucho carecéis, y sois
} 
A su vez, en el sintagma "buena policía” el elemento definitorio "policía” alude al hecho de que el grupo ordenado por este régimen es un grupo social y político, o en otras palabras, alude al hecho de que su grupo sobrepasa en número y complejidad las formas nucleares de convivencia natural o necesaria como son la familia, la economía doméstica o la parentela (supongo, pues, que ya en esto hay un marcado elemento aristotélico que se remonta a la 'arqueología' de lo político que Aristóteles ofrece en su Politica 1252a).

Con todo, Quiroga insiste en que la buena policía, así concebida, "es la que todo lo ordena, y sin la cual ninguna cosa ni conversación humana puede haber bien ordenada y que no sea corrupción" ( $\mathrm{IeD}, 153 / 154)$.

\section{La teoría de la guerra justa en Quiroga}

EN CUANTO a Los bárbaros QUe CARECEN de todo orden social identificable como buena policía y que Cayetano, según la opinión de Quiroga, omite en su taxonomía de los infieles, la Información en Derecho advierte que nada impide someterlos para imponerles un régimen político,

aunque no nos molesten a nosotros ni impidan paso ni nos tengan tomada cosa nuestra ni que nos pertenezca ni sean enemigos del nombre cristiano [o sea: aunque no se den las justificaciones de guerra provistas por la Segunda Provisión]. Pues que basta vivir en notoria ofensa de Dios su Criador, y en culto de muchos y diversos dioses, y contra ley natural y en tiranía de sí mismos, como gente bárbara y cruel y en ignorancia de las cosas y del buen vivir político, y sin ley ni rey como son estos naturales, que, además y allende de su infidelidad, eran entre sí mismos crueles, bárbaros, feroces, y aún son bárbaras naciones y sus principales tiranos contra los menores y maceoales ${ }^{7}$ que poco pueden y tienen opresos, sin tener entre sí policía alguna que fuese libre y buena como debe tener todo hombre razonable humano (IeD, 96).

Quiroga advierte más adelante, que este sometimiento o, como él mismo dice, esta 'sujeción', que busca imponer un orden social reemplazando el desorden vigen-

muy defectuosos, de que se os recrecen grandes, e irremediables males, inconvenientes, e incomodidades, así a vuestros cuerpos como a vuestras ánimas"; Ibid., p. 256: "os aprovechará también la guarda de lo dicho para que viviendo en este concierto, y buena policía fuera de necesidad, y mala ociosidad, y codicia demasiada, y desordenada, demás de salvar vuestras ánimas"; Ibid., p. 257: "en buena policía, y doctrina cristiana así moral, y de buenas costumbres, como espiritual de vuestras ánimas".

${ }^{7}$ Los 'maceoales' o 'macehaules' (del náhuatl 'macehualtin') eran, en el territorio mexicano prehispánico, los indios que ocupaban el último escalafón social y se encontraban sometidos en diferentes grados de dependencia a sus superiores. 
te en estos naturales puede efectuarse a la fuerza, si esto fuera necesario, lo cual lo convertiría entonces en una guerra justa. Una guerra justa esta, hay que repetirlo, muy diferente a la que erróneamente define la Segunda Provisión. Advierte Quiroga que su propia teoría de la legitimidad de una empresa militar contra los indios se refiere a "la sujeción y pacificación y sosiego de aquestos bárbaros [...] no para destruirlos, sino para humillarlos de su fuerza y bestialidad" (IeD, 102). A lo que añade el mismo Quiroga poco después:

Y como conviene que lo haga y mande hacer todo doctor e instruidor y apóstol, mayormente de gente bárbara como esta, [...] no para destruirlos, como nosotros lo entendemos, sino para edificarlos como su Majestad y el Sumo Pontífice lo entienden, como parece por la bula [Inter cetera de Alejandro VI] e instrucciones de ello, y como también lo dice Juan Gerson, doctor cristianísimo, [en su obra] De potestate ecclesiastica et origine iuris (IeD, 103).

Hagamos una breve síntesis de lo visto hasta ahora:

(1) Según Quiroga, no se les puede hacer la guerra justa a los indígenas sirviéndose de los títulos legitimatorios especificados en la Segunda Provisión (a saber: rebelión, resistencia a la predicación cristiana, etc.).

(2) La conversión de los indígenas es una conditio sine qua non para justificar la presencia española en el Nuevo Mundo, pero se debe llevar a cabo sin recurrir a la fuerza, tal y como lo advierte Cayetano en el pasaje citado por Quiroga.

(3) Asimismo, Cayetano en un principio tiene razón al afirmar que no hay guerra justa contra los infieles que viven en territorios nunca antes gobernados por cristianos.

(4) Cayetano omite, sin embargo, el caso de los infieles cuya barbarie impide que vivan como seres humanos propiamente dichos. ${ }^{8} \mathrm{El}$ elemento clave que indica la carencia de legítimo autogobierno en estos bárbaros es su falta completa de buena policía.

(5) Refiriéndose a este cuarto punto, Quiroga advierte que este es el caso de los pueblos del Nuevo Mundo. Estamos entonces hablando de un grupo de infieles

\footnotetext{
${ }^{8}$ Recuérdese, como lo hace también Quiroga, que Cayetano se refiere explícitamente a pueblos de infieles, cuyas autoridades, "aunque infieles, son legítimas autoridades, sea que se gobiernen de acuerdo al sistema regio, sea que se ajusten al régimen de participación ciudadana” Serrano Gassent, P., (IeD), Vasco de Quiroga: La Utopía en América, op. cit., p. 94.
} 
que, según la interpretación de Quiroga, no aparece en la taxonomía de infieles de Cayetano. Y es por eso que, más adelante, Quiroga va a proponer que, siempre de acuerdo con la autoridad de Cayetano, pero, sin embargo, contra la teoría de la Segunda Provisión, se los pueda conquistar en guerra justa si fuera necesario, para imponerles un régimen político del que carecen en su estado de indigencia respecto a una buena policía.

Mas, a estas alturas del argumento, por supuesto que surge una pregunta inevitable: ¿Cuál es el criterio de buena policía que subyace a la argumentación de Quiroga en relación con los indígenas? En otras palabras: ¿Cómo justifica Quiroga su opinión de que no había (ni jamás había habido) buena policía en los pueblos del Nuevo Mundo? Es decir, ¿cómo se justifica que no había ni hubo anteriormente un modo aceptable y humano de (auto)gobierno entre los pueblos del Nuevo Mundo? Es en este contexto en el que aparece Aristóteles de la mano de Juan Gerson.

\section{Las "tres maneras de buena policía" según Aristóteles}

En el tercer capítulo de la Información en Derecho, Quiroga hace mención varias veces del Tractatus de potestate ecclesiastica et de origine iuris et legum de Juan Gerson. ${ }^{9}$ Es importante notar que, en las consideraciones de Quiroga, la doctrina aristotélica de las formas de gobierno legítimas y positivas - que Quiroga equipara, e incluso tiende a identificar, con las maneras de buena policía - se introduce exclusivamente a través de lo que de ella se encuentra en Gerson, a quien Quiroga llama explícitamente "doctor cristianísimo" en varias ocasiones (IeD, 77; 96; 103). Obviamente, Quiroga se refiere aquí a Gerson en su descargo en medio del acalorado debate de aquellos momentos sobre si se podía recurrir a Aristóteles como autoridad en materia de política indiana. ${ }^{10}$ Sea como fuese, se puede constatar que en la fundamentación teórica de la buena policía Quiroga aduce y se inclina por

\footnotetext{
${ }_{9}$ Gerson J., De ecclesiastica potestate et de origine juris et legum, Paris, 1474. Quiroga se refiere a este tratado en IeD, 96, 98 y 103, y lo cita textualmente en IeD, 104.

${ }^{10}$ Doctor christianissimus es el título tradicional conferido a Gerson. Pero queda muy claro que aquí como en otras ocasiones, Quiroga emplea el sobrenombre 'cristianísimo' específicamente para probar la ortodoxia de ciertas opiniones a través de Gerson. A su vez, la autoridad de Aristóteles, en la mayoría de los casos, fue discutida y atacada sobre todo en cuanto a la defensa de la doctrina sobre la 'esclavitud natural' de los bárbaros, doctrina elaborada por Aristóteles en su Política (1252a-1254b) y aplicada a los indígenas americanos por algunos de los tratadistas de la época de la Conquista: cf. Schäfer, C., "La Política de Aristóteles y el Aristotelismo político del siglo XVI", Ideas y Valores 119, 2002, pp. 109-135.
} 
una doctrina netamente aristotélica, a saber, que hay "tres maneras en que se divide y puede dividir toda buena policía" (IeD, 96), pero la introduce deliberadamente apoyándose en Juan Gerson, quien la expone en la consideración décimo tercera de su tratado. ${ }^{11}$ La teoría aristotélica correspondiente se encuentra en la Política (1279ab) y la Ética a Nicómaco (1160a-1161a). Es preciso decir que, en lo que Quiroga expone, se conserva muy bien un rasgo típico del texto aristotélico, que es la pretensión de abarcar todas las posibilidades concebibles de un tema en una sola definición o clasificación. Esta exhaustividad queda claramente reflejada al caracterizar las distintas posibilidades que presenta como aquellas "en que se divide $y$ puede dividir toda buena policía". De hecho, Aristóteles insiste, y el texto de Gerson abunda en esta insistencia, en que solamente puede haber tres géneros de buen gobierno, (expresión que Quiroga traduce como "tres maneras de buena policía" ${ }^{12}$ ) y no más:

(1) El primero de estos géneros o formas de buen gobierno es la monarquía, que Quiroga define como la "congregación de muchos perfecta, debajo de obediencia o sujeción de uno, según sus leyes y ordenanzas [...], el cual no tenga [en cuenta] principalmente el bien propio particular suyo [...], sino el pro y bien común de todos" (IeD, 97). De esta definición se desprende fácilmente cuál es la manera de mala policía que constituye la forma degenerativa de la monarquía, a saber, la tiranía. Lo malo de esta última "manera de policía" no reside en el hecho de constituir un gobierno de una persona, sino en que esta persona, el tirano, actúa principal o exclusivamente en su propio beneficio e interés y gobierna a su antojo sin leyes ni ordenanzas (IeD, 97);

(2) el segundo género de buena policía, la aristocracia, se caracteriza por ser una "congregación perfecta, so obediencia de pocos que entienden y pretenden principalmente el bien de la cosa pública y la rijan y ordenen por sus leyes y ordenanza" (IeD, 97);

$y$, finalmente,

${ }_{11}$ De hecho, las doce consideraciones primeras del Tractatus de potestate ecclesiastica et de origine iuris et legum versan sobre la potestad eclesiástica y sólo la consideración decimotercera (y última) está dedicada al tema del origen del derecho y de las leyes (en la edición Estrasburgo 1488 de las obras de Gerson, incluso los titulillos de las páginas de la consideración decimotercera dejan de ser De potestate ecclesiastica y pasan a ser De origine iuris). Lo que Quiroga dice sobre la doctrina aristotélica de las formas de gobierno reproduce casi ad verbum lo que escribe Gerson en las col. antepenúltima y penúltima de la consideración decimotercera de dicha edición.

12 Que Quiroga hable de “maneras” en vez de “géneros” de buena policía, deja entrever que en la teoría quiroguiana de buena policía la "policía" se concibe más como un nomen agentis que como un nomen acti, es decir, se concibe más como "conducta” (moral) que como "constitución” (política). 
(3) el tercero, que Quiroga llama "policía propiamente hablando", y que en Aristóteles es la democracia o timocracia, ${ }^{13}$ se caracteriza por el hecho de que el bien común es entendido por muchos o, incluso, por todos y procurado por ellos a través de sus leyes y ordenanzas (cf. IeD, 97).

Con todo, resulta obvio que el concepto de policía, tal como se encuentra en Quiroga, es dicotómico. O mejor dicho, para definirlo hay que servirse por lo menos de dos diferenciaciones que también encontramos en Aristóteles (Política 1279a): la primera, que concierne a lo que podríamos llamar la diferencia específica formal dentro del género de las variaciones de las distintas maneras de gobierno, distingue tres subgéneros de acuerdo con la cantidad de personas que están al mando de la comunidad. Así tenemos que los gobiernos pueden ser gobiernos de uno, de pocos y de muchos o, incluso, de todos. La segunda, que se refiere a lo que podríamos llamar la diferencia específica material ${ }^{14}$, enfoca el aspecto cualitativo y determina si la policía es buena, es decir, aceptable para la humanidad y válida según el estándar de la justicia y de la ley natural y de la lógica intrínseca de toda idea de gobierno. Si no lo es, a saber, si pasa por alto el bien del animal racional político, o lo que es lo mismo, si obvia que el hombre es un ser racional y libre por naturaleza, y si, por tanto, se viola el principio de que toda policía debe estar al servicio del bien común, ${ }^{15}$ estaremos ante una mala policía. Este uso sinecdoquético de los conceptos políticos es una herencia del texto aristotélico transmitida por los comentarios medievales y repetida en Gerson: de esta manera, reino y tiranía coinciden en ser monarquías, si contemplamos el lado cuantitativo formal, pero si contemplamos el lado cualitativo, son maneras de gobernar opuestas. ${ }^{16}$ También en esto, pues, la teoría de Quiroga se atiene a la doctrina aristotélica expuesta en la Política. En Quiroga, el criterio decisivo para valorar si la policía en cuestión observa esta propiedad del gobierno legítimo parece ser la adopción de leyes y ordenanzas que respondan a la verdadera comprensión del bien común por parte de la(s) persona(s) que está(n) al mando de la comunidad. Lo cual, sorprendentemente, es una concepción más

${ }_{13}$ En su nota al margen correspondiente a este pasaje (Serrano Gassent, P., (IeD), Vasco de Quiroga: La Utopía en América, op. cit., p. 98 nota 12), Quiroga nombra las malas policías, "tiranía, oligarcia [sic], democracia", siendo la timocracia el gobierno bueno de muchos. Sin embargo, las denominaciones pueden variar, siendo a veces la democracia una forma buena y la oclocracia su correspondiente degeneración.

14 'Material' aquí se entiende en el sentido que también subyace, por ejemplo, la expresión 'materia de estado', es decir (según la definición del Diccionario de la RAE): "Conjunto de las cosas que atañen al gobierno, conservación, aumento y reputación de los Estados".

${ }^{15}$ Recuérdese el criterio que menciona Quiroga, Ibid, p. 96: una "policía [...] que fuese libre y buena como debe tener todo hombre razonable humano".

${ }^{16}$ Cf. Stengel, B., Der Kommentar des Thomas von Aquin zu Politik des Aristóteles, Marburg, Tecum, 2011, p. 257 , con citas pertinentes del comentario de Tomás de Aquino a la Ética a Nicómaco y a la Política de Aristóteles. 
platónica que aristotélica. En este sentido, el texto de Gerson deja entrever un cierto trasfondo de agustinismo platónico. Quiroga, empero, complementa el criterio intelectualista mencionado de la correcta comprensión, que rige las concepciones de los filósofos antiguos, con un aspecto voluntarista muy típico de su época. $Y$ es que él siempre habla - casi a la manera de un hendíadis - de "entender y pretender" el provecho ("pro") común como base de la buena policía (por ejemplo, IeD, 97). ${ }^{17}$

A Quiroga le constaba que todas las formas de gobierno que existían entre los indígenas del Nuevo Mundo eran malas policías en la medida en la que constituían formas de gobierno que, por un defecto estructural y no sólo accidentalmente, ni entendían ni pretendían el bien común. Lo que a algunos tratadistas de la época les hacía creer que los naturales del Nuevo Mundo tenían policías, si no buenas, sí al menos aceptables era, según el modo de ver de Quiroga, la coincidencia en el criterio de diferenciación formal-cuantitativa, es decir, las variedades de gobierno por parte de uno solo o de pocos o por parte de muchos - concepto que aparecía en el texto citado de Cayetano. Quiroga mismo, por su parte, aunque nunca pone en duda que de hecho haya habido formas de gobierno entre los indígenas, insiste en que no había policía entre ellos que cumpliese con los aspectos básicos que, según la diferenciación material-cualitativa, se requieren para la buena policía. De acuerdo con este razonamiento, Quiroga niega que entre los indios haya habido un suficiente entendimiento del bien común o una suficiente voluntad de procurarlo o, más aun, ni una cosa ni la otra, y pone como ejemplo ilustrativo más notorio el caso de

Moctezuma, que fue el que presidía entre ellos [i.e. los pueblos de la Nueva España] cuando esta tierra se ganó, a quien acataban y tenían como a Dios [y quien] tenía las condiciones del uno malo, y no del uno bueno que Gerson dice, porque así acontecía que él era adorado y tenido y reverenciado no como hombre humano, de gente libre, sino casi como Dios de gente cautiva, opresa y servil, que son las condiciones del uno malo y tirano; y quería y trabajaba que sus súbditos ni pudiesen ni supiesen ni entendiesen $(\mathrm{IeD}, 98)^{18}$.

Lo mismo cabe decir, mutatis mutandis, de la mala policía en el gobierno, ya sea de pocos o de muchos, que se pudiera dar entre los indígenas ( $\mathrm{IeD}, 99-100)$. Concluye Quiroga:

\footnotetext{
${ }_{17}$ En contraste, el texto de Gerson, fiel a la versión que el Aristoteles Latinus da del original griego skopei, tiene intendit, o sea 'mira a', 'contempla', 'presta atención a'. El sintagma 'entender y pretender' en Quiroga ańade un aspecto de esfuerzo y autodirección voluntativa.

${ }_{18}$ Abundan en Quiroga los pasajes que se refieren al hecho que los caciques y reyes prehispánicos eran venerados (casi) como dioses por los indígenas, mientras que éstos al mismo tiempo se rebajaban y se autohumillaban hasta un nivel infrahumano. Me parece obvio que Quiroga con esto alude al famoso locus classicus de la Política (1253 a 28), donde Aristóteles dice que el hombre que vive sin polis es o un dios o un animal.
} 
Estas maneras todas de policías buenas y malas, que pone Aristóteles y refiere en el lugar dicho Gerson, yo las tengo cotejadas con las que he visto entre estos naturales, y las primeras tres libres y buenas, a mi ver, no las hay entre ellos, y las otras postreras tres serviles y malas, todas las tienen, que ninguna les falta, si no me engaño; y entre algunos ni buenas ni malas, sino que están como bestias por los campos, siendo en la verdad naturalmente tan capaces los unos como los otros (IeD, 98).

\section{La "buena policía mixta" como remedio propuesto por Quiroga}

Partiendo De LO DiCho hasta AQuí, se explica fácilmente la conclusión a la que llega Quiroga en cuanto a la legitimidad de la conquista: mientras que la mayoría de los tratadistas, y entre ellos Gerson, a quien Quiroga se opone sólo en este punto, mantiene que el dominio de los infieles sobre sus territorios es legítimo y debe respetarse, Quiroga determina que no se pueden ni se deben respetar aquellas formas de dominio que puedan ser calificadas como mala policía. Al contrario: hay que abolirlas. ${ }^{19}$ La causa es que las formas de mala policía contradicen enteramente el sentido del gobierno y de autoridad política, es decir, no alcanzan lo que 'debe ser', en su idea, todo gobierno y, con ello, lo pervierten, lo que conlleva una anulación de toda legitimidad de un dominio semejante.

Para tenerlo muy claro: no es el caso que no hubieran sido formas de dominio. Quiroga nunca niega que Moctezuma haya dominado a su pueblo. Niega que la forma de dominio en cuestión haya sido una forma de gobierno o autoridad. El trasfondo teórico se hace obvio en la calificación de mala policía y buena policía que Quiroga confiere a las diferentes formas de dominio: es la teoría del mal como privación del bien. En esta teoría, lo malo no es la negación del bien. Más bien, el mal es visto como una limitación, ausencia o deficiencia del bien en la medida que disminuye los parámetros esenciales de una cosa buena de tal manera que esta cosa, siendo siempre la misma, ya no se parezca a sí misma por la falta de rasgos naturalmente correspondientes a ella. Como en el famoso caso platónico de un cuchillo que esencialmente es un instrumento para cortar y picar, y que, una vez privado de sus calidades de ser afilado y agudo, siendo el mismo objeto, es un mal cuchillo y, en el más extremo de los casos de la pérdida total de estas calidades, ya no se puede considerar un cuchillo para nada. Es el caso extremo del que habla Quiroga en

\footnotetext{
${ }_{19}$ Con razón observa Serrano Gassent, P., Vasco de Quiroga: La Utopía en América, op. cit., p. 29, al respecto: "Su argumentación se hallaba en este punto próxima a la de la junta de 1511, la de Palacios Rubios y Matías de Paz" (la "junta de 1511" es la reunión convocada por Fernando el Católico, cuyos resultados desembocaron en las Leyes de Burgos de 1512).
} 
cuanto a la policía: el caso de un gobierno que, si bien se puede todavía considerar una forma de dominio, carece de todas las cualidades de una buena policía en tal medida que ya no se puede considerar una forma de policía para nada.

Poniéndolo en términos de la taxonomía de Cayetano: los gobernantes prehispánicos de los infieles del Nuevo Mundo, si bien eran señores de hecho, nunca lo eran de iure, su dominio efectivo carecía de autoridad, ya que la justificación de base, a saber, el procurar el bien común, estaba ausente en su caso. Por ende, es legítimo quitarles sus poderes e imponer un nuevo orden político, pero sólo a condición de que este sea una buena policía. Así queda justificada no sólo la presencia de los españoles en el Nuevo Mundo, sino también la conquista militar, que en tal caso se convertiría inmediatamente en una guerra justa. Esta guerra sería entonces algo análogo a un tiranicidio, pero llevada a cabo de manera colectiva, y se parece en muchos sentidos a la acción militar de la política internacional de nuestro siglo contra ciertos 'warlords' africanos.

La conclusión de Quiroga es, por tanto, esta:

Contra estos tales y para este fin y efecto, cuando fuerzas hubiese, por justa, lícita y santa, servatis servandis, tendría yo la guerra, o, por mejor decir, la pacificación o compulsión de aquéstos, Non in destructionem sed in aedificationem, como lo dice San Pablo, 2a a los Corintios 22 (IeD, 102 - Quiroga se equivoca: La cita es de 2 Cor 10,8).

Lo cual, al parecer de Quiroga, debe ser una empresa conjunta del poder espiritual y seglar, "no para destruirlos, como nosotros lo entendemos, sino para edificarlos como su Majestad y el Sumo Pontífice lo entienden" (IeD, 103).

A propósito de la íntima relación de lo espiritual y lo seglar en Quiroga, vale añadir una última observación. Quiroga escribe su Información en Derecho no sólo para denunciar los fallos y defectos de la anterior administración de la Nueva España y de la Segunda Provisión. Más bien, quiere proponer medidas viables para remediar las deficiencias jurídicas, políticas y morales que analiza. Por eso, en lo que es el pasaje tal vez más célebre de su Información en Derecho, propone sus propias ideas para implementar una forma de buena policía en la Nueva España.

El texto de Quiroga deja entrever que uno de los modelos posibles para proporcionarles un buen gobierno a los indígenas podría haber sido en teoría el ya establecido por el régimen de la encomienda. Quiroga, en un principio, reconoce los méritos de la idea básica del régimen encomendero: repartir el territorio conquistado entre españoles, los cuales se ocuparán de los indios del lugar, reemplazando la mala policía de los caciques por una buena policía basada en sanas convicciones cristianas. De acuerdo con el análisis de Quiroga, el gran problema del sistema encomendero tiene un doble aspecto. En primer lugar, por supuesto, la depravación moral 
de los encomenderos, que los llevan al maltrato prácticamente sistemático de los indígenas confiados a ellos. En segundo lugar, y más importante si cabe en cuanto al proyecto quiroguiano de proponer una solución propia al tema de la mala policía, la encomienda, como medida política, peca de no representar un sistema de policía mixta o, al menos, de no representarlo suficientemente bien. Por policía mixta, Quiroga entiende, siempre de acuerdo con su idea clave de una buena policía, un régimen que procure el bien tanto material como espiritual de todos los miembros de la comunidad en cuestión. ${ }^{20} \mathrm{La}$ encomienda defrauda especialmente el segundo propósito, el de procurar el bien espiritual de los indígenas, y esto representa una omisión injustificable e, incluso, podría decirse, un irremediable y grave error:

Y si esta buena policía es necesaria para la buena gobernación en la solamente seglar, que será en la policía que es y ha de ser de necesidad de obligación policía mixta, que en todo ha de poner orden y concierto de nuevo así en lo espiritual como en lo temporal, en que de necesidad se ha de proveer en esta tierra y Nuevo Mundo por su Majestad y sus ministros, pues Dios le ha hecho apóstol de lo uno y rey de lo otro, y dar para en todo no muy buen estado y corte de república cristiana y católica, en que haya buena y general conversión y bastante sustentación para todos, españoles y naturales, con conservación de ellos y de la tierra; y esto que sea por tales modos, medios y arte, y por tales leyes y ordenanzas, que se adapten a la calidad y manera y condición de la tierra y de los naturales de ella, de manera que ellos las puedan saber, entender y usar, y guardar y ser capaces de ellas; y de esta manera son las de mi parecer, sin los intrincamientos y oscuridad y multitud de las nuestras, que no las sabrán ni entenderán ni serán capaces de ellas de aquí al fin del mundo, ni se las adaptaran cuantos son nacidos (IeD, 100-101).

La solución propuesta por Quiroga de una buena policía mixta para pequeñas comunidades básicas según el modelo de los pueblos-hospitales que Quiroga mismo fundó, al inicio concebidas como núcleos y modelos de formas de convivencia más extensas, y que serían aplicables posteriormente a todos los territorios de la Nueva España, ha sido definida como utópica, y no sin razón: esta solución muestra rasgos utópicos en cuanto constituye una severa crítica a las circunstancias sociales y políticas vigentes en su momento, propone un estado político ideal que claramente contrasta con las circunstancias que se han criticado, abre la puerta e, incluso, invita a la acción para remediar esta contradicción, y, de hecho, se inspira

\footnotetext{
${ }^{20}$ Cf. Serrano Gassent, P., (IeD) Vasco de Quirga: La Utopía en América, op. cit., p. 223: "Y digo que esta falta e inconveniente en esta tal arte de república, como es la de mi parecer, no la habría ni podría haber, ni cabe ni ha lugar en ella, porque es arte de policía mixta, como la cose de esta tierra lo requiere y ha menester; pues por ella se ordena y ha de ordenar todo, así en lo temporal como en lo espiritual, por el apóstol de ella, que es su Majestad. Y así se provee por ella en lo uno, que no se olvida ni descuida en lo otro, antes quedando ordenado lo de buena policía y conversaciones humanas, también quedan cortadas las raíces de toda discordia y desasosiego y de toda lujuria y codicia y ociosidad y pérdida de tiempo mal gastado, y se introduce la paz y justicia [...]”.
} 
en todo ello explícitamente en el prototipo textual del género utópico, a saber, en la obra De optimo reipublicae statu de Tomás Moro. ${ }^{21}$ No hay tiempo para ahondar en este asunto, por más interesante que sea, y por más que complemente, de manera sorpresiva, quizás, la perspectiva aristotélica del pensamiento social quiroguiano. Más bien, ya es tiempo de llegar a una conclusión.

\section{Conclusión: las fuentes aristotélicas}

EVALUANDO LOS RESULTADOS UN TANTO HETEROGÉNEOS ahora obtenidos, el papel de Aristóteles para el razonamiento sobre la buena policía en el Nuevo Mundo que está contenido en la Información en Derecho se hace sin embargo suficientemente patente: la cuestión de la guerra justa, instrumento legitimador para la esclavización de los indígenas contemplado por la Segunda Provisión, conduce al problema de la 'buena policía'. Quiroga no mantiene que la esclavización se justifique sin más en virtud de una guerra justa. Pero considera justificada la conquista de pueblos faltos de buena policía. El criterio decisivo de tener una buena policía, el cual rige todo el razonamiento quiroguiano, lo aporta Aristóteles por mediación de Juan Gerson. Este criterio demuestra con gran vigor que lo 'bueno' de la 'buena policía' no solamente aporta una cualidad extrínseca y candorosa como en el caso del 'buen chico' o de un 'buen almuerzo'. Más bien, los términos 'buena policía' y 'mala policía' en Quiroga denotan formas de existencia comunitaria que, comparables a la eudaimonia y la kakodaimonia, el vivir según (o guiado por) un buen espíritu y el vivir según (o guiado por) un mal y pernicioso espíritu, de los antiguos, representan el logro contundente o el fracaso total y detestable de un proyecto de vida. Quiroga estima que Aristóteles, en su Política y su Ética a Nicómaco, elabora y presenta un cuadro completo de los géneros de buena y mala policía. En este sentido, identificando las formas de gobierno reales de los pueblos indígenas pre-hispanos con los diversos géneros aristotélicos de mala policía, Quiroga encuentra un motivo justificatorio para la presencia e, incluso, para la acción militar de los españoles en el Nuevo Mundo. Al mismo tiempo, los tres factores representados por la intacta naturaleza de los indios, la abolición de las formas de mala policía habidas entre los indígenas y la destrucción de las antiguas formas de estructuración social en el proceso de co-

\footnotetext{
${ }^{21}$ Son estos los elementos definitorios del concepto de utopía según el detallado estudio de Schölderle, Th., Utopía und Utopie: Thomas Morus, die Geschichte der Utopie und die Kontroverse um ihren Begriff, Baden-Baden, Nomos, 2011, pp. 479-481. Serrano Gassent, P., Vasco de Quirga: La Utopía en América, op. cit., pp. 18-19, desde un análisis tomado de Horkheimer, llega a un elenco semejante de elementos fundamentales de lo utópico y los aplica a la cuestión quiroguiana.
} 
lonización, configuran la idea quiroguiana del Nuevo Mundo como tabla rasa, idea que invita a la empresa (utópica, si así se quiere) de establecer en el Nuevo Mundo formas de convivencia humana de acuerdo a la concepción de la buena policía mixta que Quiroga desarrolla a partir de la teoría político-filosófica aristotélico-gersoniana y, en un segundo momento, de acuerdo con la sociedad utópica descrita por Tomás Moro. Con esto, Quiroga, de una manera muy peculiar, entrelaza el aristotelismo político realista con el idealismo utópico de su época. Esta concepción tan extrañamente "utópica" y a la vez pragmática se concreta en la instauración de los pueblos-hospitales quiroguianos, ideados por su fundador según el patrón de la isla Utopia de Tomás Moro como modelos sociales para el Nuevo Mundo y, quizás, como núcleos de organizaciones políticas ulteriores todavía más amplias. ${ }^{22}$

Llegamos así a la conclusión de que por más llamativas y hasta extravagantes que pudieran parecer las posturas de Quiroga sobre la guerra justa y la buena policía en el Nuevo Mundo, estas posturas, así como también su adhesión a las ideas utópicas de Moro, se encuentran impregnadas por teorías tradicionales típicamente aristotélicas, las cuales constituyen, sin que Quiroga lo tematice, el fundamento tanto de su pensamiento utópico como de sus convicciones prácticas.

${ }^{22}$ Cf. Ibid., pp. 18-24. 


\section{Referencias Bibliográficas}

Aristoteles, Politica, edited by W.D. Ross. Oxford, Oxford University Press, 1957. doi: 10.1093/oseo/instance.00259280 , https://doi.org/10.1093/oseo/ instance.00259280

Baker-Smith, D., Reading Utopia. En G.M. Logan (ed.): The Cambridge Companion to Thomas More. Cambridge, CUP, 2011. doi:10.1017/CCOL9780521888622.009, h https://doi.org/10.1017/ CCOL9780521888622.009

Gerson, J., De ecclesiastica potestate et de origine juris et legum, Paris, 1474.

Martín Hernández, F., Vasco de Quiroga, Salamanca, Publicaciones UPS, 1993.

Pagden, A., Spanish Imperialism and the Political Imagination: Studies in European and Spanish-American Social and Political Theory, 1513-1830, Boston, Yale University Press, 1998.

Quiroga, Vasco de, Información en Derecho. En P. Serrano Gassent (2002), Vasco de Quiroga: La Utopía en América, Madrid, Dastin, 2002, 69-249. [= IeD]

Quiroga, Vasco de, Reglas y Ordenanzas para los Pueblos-Hospitales de Santa Fe, 2002. En Serrano Gassent, P., Vasco de Quiroga: La Utopía en América, Madrid, Dastin, 2002, 251-274. [= RyO].

Sabido Sánchez Juárez, C., "El programa humanista en la utopía práctica de Vasco de Quiroga”. En V. Aspe Armella (comp.), Tomás Moro y Vasco de Quiroga. Utopías en América, Pamplona, EUNSA, 2018, 115-135.

Schäfer, C., "La Política de Aristóteles y el Aristotelismo político del siglo XVI", Ideas y Valores 119, 2002, 109-135.

Schölderle, Th., Utopia und Utopie: Thomas Morus, die Geschichte der Utopie und die Kontroverse um ihren Begriff, Baden-Baden, Nomos, 2011. doi: 10.5771/9783845229331, https://doi.org/10.5771/9783845229331

Serrano Gassent, P., Vasco de Quiroga: La Utopía en América. Madrid, Dastin, 2002.

Stengel, B., Der Kommentar des Thomas von Aquin zur Politik des Aristoteles, Marburg, Tectum, 2011.

Villaseñor, R., "Luciano, Moro y el utopismo de Vasco de Quiroga", Cuadernos Americanos 4/4, 1942, 155-175. 
Zorroza, M.I., "La utopía renacentista y el modelo de Vasco de Quiroga". En V. Aspe Armella (comp.), Tomás Moro y Vasco de Quiroga. Utopías en América, Pamplona, EUNSA, 2018, 97-113.

DOI: https://doi.org/10.15366/bp2021.26.002

Bajo Palabra. II Época. No26. Pgs: 39-58 